\title{
Influence of low contents of superhydrophilic MWCNT on the properties and cell viability of electrospun poly (butylene adipate-co-terephthalate) fibers
}

\author{
Bruno V.M. Rodrigues ${ }^{\mathrm{a}, 1}$, Aline S. Silva ${ }^{\mathrm{a}, 1}$, Gabriela F.S. Melo ${ }^{\mathrm{b}}$, Luana M.R. Vasconscellos ${ }^{\mathrm{b}}$, \\ Fernanda R. Marciano ${ }^{a}$, Anderson O. Lobo ${ }^{\mathrm{a}, *}$ \\ a Laboratory of Biomedical Nanotechnology, Institute of Research and Development (IPEDD), University of Vale do Paraiba (UNIVAP), Av. Shishima Hifumi 2911, Sao Jose dos Campos, \\ Sao Paulo, Brazil \\ b Department of Bioscience and Oral Diagnosis, Institute of Science and Technology, Sao Paulo State University (UNESP), Av. Engenheiro Francisco Jose Longo 777, Sao Jose dos Campos, \\ Sao Paulo, Brazil
}

\section{A R T I C L E I N F O}

\section{Article history:}

Received 8 July 2015

Received in revised form 7 October 2015

Accepted 23 October 2015

Available online 26 October 2015

\section{Keywords:}

PBAT

Nanocomposites

Electrospinning

Superhydrophilic MWCNT

Mechanical properties, osteogenesis

\begin{abstract}
A B S T R A C T
The use of poly (butylene adipate-co-terephthalate) (PBAT) in tissue engineering, more specifically in bone regeneration, has been underexplored to date due to its poor mechanical resistance. In order to overcome this drawback, this investigation presents an approach into the preparation of electrospun nanocomposite fibers from PBAT and low contents of superhydrophilic multi-walled carbon nanotubes (sMWCNT) (0.1-0.5 wt.\%) as reinforcing agent. We employed a wide range of characterization techniques to evaluate the properties of the resulting electrospun nanocomposites, including Field Emission Scanning Electronic Microscopy (FE-SEM), Transmission Electronic Microscopy (TEM), tensile tests, contact angle measurements (CA) and biological assays. FE-SEM micrographs showed that while the addition of sMWCNT increased the presence of beads on the electrospun fibers' surfaces, the increase of the neat charge density due to their presence reduced the fibers' average diameter. The tensile test results pointed that sMWCNT acted as reinforcement in the PBAT electrospun matrix, enhancing its tensile strength (from 1.3 to $3.6 \mathrm{MPa}$ with addition of $0.5 \mathrm{wt}$.\% of sMWCNT) and leading to stiffer materials (lower elongation at break). An evaluation using MG63 cells revealed cell attachment into the biomaterials and that all samples were viable for biomedical applications, once no cytotoxic effect was observed. MG-63 cells osteogenic differentiation, measured by ALP activity, showed that mineralized nodules formation was increased in PBAT/0.5\%CNTs when compared to control group (cells). This investigation demonstrated a feasible novel approach for producing electrospun nanocomposites from PBAT and sMWCNT with enhanced mechanical properties and adequate cell viability levels, which allows for a wide range of biomedical applications for these materials.
\end{abstract}

(c) 2015 Elsevier B.V. All rights reserved.

\section{Introduction}

In the last years, the production of scaffolds for bone tissue engineering has been extensively investigated in order to find ideal threedimensional constructs able to mimic the properties of natural bone [1-3]. For this purpose, an ideal synthetic bone material must meet some requirements such as biocompatibility, adequate mechanical properties, osteoconductivity/osteoinductivity and ability to promote bone regeneration [1].

\footnotetext{
* Corresponding author at: Laboratory of Biomedical Nanotechnology, Research and Development Institute, University of Vale do Paraiba, Avenida Shishima Hifumi, 2911 Lab 36 - IP\&D II, Brazil.

E-mail addresses: aolobo@pq.cnpq.br, lobo.aol@gmail.com (A.O. Lobo).

1 These authors contributed equally to this work.
}

Different processing techniques have been employed to fabricate scaffolds structures for tissue engineering, such as solvent casting, extrusion, porogen leaching and electrospinning [4,5]. In the field of bone regeneration, there is a crucial need to reach scaffolds architectures that are able to mimic the bone-extracellular matrix (ECM), which presents a great role in controlling cell differentiation. Furthermore, the mechanical properties of the newly tissue must be similar to those of the bone repair site, which always represents a challenge. Due to its known ability to produce 3D fibrous structures, electrospinning technique has been widely used to produce new materials aiming at applications in the field of bone tissue engineering [6,7].

Due to their excellent physical properties, high porosity and pore interconnectivity, electrospun nanofibers scaffolds present a wide range of potential applications, such as carriers for drug delivery [8], wound dressing [9], membranes [10] and tissue engineering [6]. Furthermore, the resulting fibers can undergo to downstream physical and chemical 
modification, which opens a big window for the manipulation and development of novel classes of materials. All these properties combined with the well-known ability of electrospun scaffolds to support cell adhesion and proliferation explain the high volume of studies using electrospinning as primary technique to produce fibrous scaffolds for tissue engineering [6].

Several biopolymers from natural and synthetic origins, with special attention to polyesters, have been widely investigated towards their potential for biomedical applications, more specifically in tissue engineering [11]. A few examples of synthetic polyesters often utilized for 3D scaffolds preparation include poly ( $\varepsilon$-caprolactone) (PCL) [12], polylactic acid (PLA) [13], polyglycolic acid (PGA) [14], and more recently poly (butylene adipate-co-terephthalate) (PBAT), which was used as the starting material in the present work [15].

PBAT (Fig. 1), also known as polybutyrate, is a random copolymer synthetized through a transterification reaction between the polyesters of adipic acid and dimethyl terephthalate. PBAT is very flexible and possess a range of interesting properties, such as biodegradability and high elongation at break [16]. However, the poor mechanical resistance of PBAT is a drawback that limits its medical applications in some sectors such as bone implants. In order to enhance its mechanical properties, investigations have focused on blending PBAT with other polymers or associating it with reinforcement agents. A few recent examples are the preparation of PBAT/potato starch blends [17], PBAT/starch blends with pMDI as compatibilizer [18], PBAT/CNTs composites via meltblending process [19] and PBAT with nanofibrillated cellulose as reinforcement [20] and PBAT/hydroxyapatite composites structures for bone tissue recovery [21]. However, to date materials from the electrospinning of PBAT have received little attention related to their preparation and application.

Carbon nanotubes (CNTs) are extremely strong and stiff nanostructures of carbon atoms arranged in a cylindrical hexagonal network and often categorized in two different groups: single-walled carbon nanotubes (SWCNT) and multi-walled carbon nanotubes (MWCNT) $[22,23]$. SWCNT present the fundamental cylindrical structure (singlewalled) whereas the latter consists in a junction of two or more coaxial cylinders in a layer-by-layer nanostructure (multi-walled). The high aspect ratio of CNTs and consequent anisotropic geometry, plus their excellent thermal, electrical and mechanical properties make them excellent candidates to be used as reinforcement in polymeric matrices $[24,25]$. Several studies have demonstrated the increase in the mechanical properties of composites even with small amounts of CNTs [26-28].

Three major drawbacks associated with the use of CNTs are their susceptibility to agglomeration, hampering their dispersion and further distribution in the matrix, high hydrophobicity and possible cytotoxicity effects at high concentrations. Thus, several studies have focused on the development of methods to obtain better CNTs dispersion or even in the use of modified CNTs in order to reduce CNTs agglomeration and hydrophobicity. In particular, MWCNT have been extensively used in many applications in fields such as medicine [29], tissue engineering [30], drug delivery [30] and electronics [31]. Jia, Wang, Yan, Wang, Pei, Yan, Zhao and Guo [32], reporting on the cytotoxicity of SWCNT and MWCNT, showed that while SWCNT significantly impaired phagocytosis of alveolar macrophage, MWCNT (10 to $20 \mathrm{~nm}$ of diameter) induced injury only when high doses were used.
The CNTs wettability can be tuned by using different chemical and/ or physical treatments in order to functionalize their surface and break their strong hydrophobic character [33]. In this context, oxygencontaining functional groups are usually introduced on the CNTs surfaces by acid treatment [34] or oxidation [35], allowing for the control of their wettability and leading to surfaces that are more reactive. However, comparatively to the methods mentioned above, the exposure of CNTs to oxygen plasma has shown to be a more effective way to introduce both polar functional groups and roughness to their surfaces [36,37]. Beyond their hydrophilic character, these CNTs containing oxygen functional groups present excellent mechanical properties and high chemical stability. To date, our group has developed many applications employing (super)-hydrophilic CNTs produced via oxygen plasma, mainly focusing on superhydrophilic vertically-aligned CNTs (VACNT-OH) [38-40]. More recently, we demonstrated a feasible method for producing PDLLA/VACNT-OH: nanohydroxyapatite scaffolds with enhanced morphology and porosity properties [40].

Oxygen plasma treatment has demonstrated good ability to not only attach oxygen functional groups on the CNTs' surfaces, but also to promote exfoliation of these CNTs, while opening their walls and consequently exposing their fundamental structure (graphene) [41]. Thus, the introduction of polar groups would not only increase the CNTs' hydrophilicity but would be also responsible for fostering hydrogen bond interactions with the polar groups of PBAT at the interfaces of the matrix-CNTs.

In the present investigation, we focused on the preparation of electrospun nanocomposites from PBAT with low contents of superhydrophilic MWCNT (sMWCNT) and posterior evaluation of their properties through a wide range of characterizations as well as evaluation of cell viability. The use of low sMWCNT contents aimed at the generation of materials with enhanced mechanical properties and non-cytotoxicity effects. To our knowledge, this was the first time that sMWCNT were systematically evaluated as reinforcement material in electrospun PBAT matrices for the production of nanocomposite fibrous materials.

\section{Materials and methods}

\subsection{Materials}

BASF SE kindly provided the commercial pellets of PBAT (Ecoflex® F Blend C1200) used in this investigation. The chemicals reagents used in this work were dimethylformamide (DMF, Synth), chloroform (Synth), isopropyl alcohol (Sigma Aldrich), ethanol (Sigma Aldrich), hydrochloric acid ( $\mathrm{HCl}$, Sigma Aldrich, $\mathrm{Co}$ ), thiazolyl blue tetrazolium bromide [3-(4,5dimethylthiazol-2-yl)-2,5-diphenyltetrazolium bromide] (Sigma Aldrich, Co), all used as received.

\subsection{Production and characterization of superhydrophilic MWCNT (sMWCNT)}

Initially, MWCNT were prepared as described in previous studies [42]. A mixture of camphor $\left(\mathrm{C}_{10} \mathrm{H}_{16} \mathrm{O}, 84 \mathrm{wt} . \%\right)$ and ferrocene (Fe $\left.\left(\mathrm{C}_{5} \mathrm{H}_{5}\right)_{2}, 16 \%\right)$ as catalyst were placed in a thermal chemical vapor deposition (CVD) furnace and vaporized at $220^{\circ} \mathrm{C}$ in an antechamber.

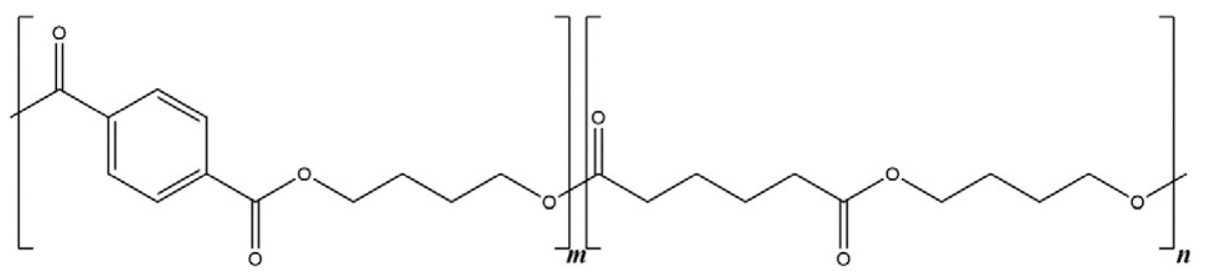

Fig. 1. Chemical structure of poly (butylene adipate-co-terephthalate). 
The vapor was carried to the chamber of the CVD furnace $\left(850^{\circ} \mathrm{C}\right)$ under argon gas flow, at atmospheric pressure, allowing for the deposition of MWCNT along the wall of quartz tube [43]. Ultrasound irradiation during $5 \mathrm{~h}$ in $\mathrm{HCl} 10 \mathrm{M}$ (acid etching) was used to removal the catalytic particles from the MWCNT, which were subsequently water washed and dried. Oxygen-containing functional groups were incorporated using a pulsed-direct current plasma reactor under oxygen flow $(1 \mathrm{sccm})$, at a pressure of $85 \mathrm{mTorr}$, under $-700 \mathrm{~V}$ and pulse frequency of $20 \mathrm{kHz}$, as described elsewhere $[44,45]$.

\subsection{Prior study of the physical-chemical properties of the solvent system}

Chloroform and DMF composed the solvent system for PBAT dissolution and posterior electrospinning. In order to establish the optimal proportion, different ratios of chloroform and DMF (50/50, 60/40, 75/25 and $85 / 15$, respectively) were studied. A Force Tensiometer Easy Dyne (K20, Krüss) was used to measure the density and surface tension of the solutions.

\subsection{Electrospinning process: preparation of PBAT/CNTs nanocomposites}

Electrospinning was performed from solutions containing PBAT $12 \mathrm{wt} . \%$ and different concentrations of sMWCNT ( 0.1 and $0.5 \mathrm{wt} . \%$, further referred as PBAT $/ 0.1 \% C N T$ s and PBAT $/ 0.5 \% C N T s$, respectively) using chloroform/DMF (60/40) as solvent system. A control sample was also considered (PBAT 12 wt.\%, referred only as PBAT). In a typical experiment, PBAT (in pellets) was dissolved in chloroform during $120 \mathrm{~min}$ under vigorous stirring while the sMWCNT were dispersed in DMF under sonication (VCX 500 - Sonics) during 60 min. After the dispersion, the sMWCNT in DMF were added to the PBAT solution, under stirring, during $20 \mathrm{~h}$ until complete homogenization. Prior electrospinning, the resulting solutions were characterized via Force Tensiometer (density and surface tension, Section 2.3) and the dynamic viscosity was measured using an Anton-Paar AMVn Automated Microviscometer. Electrospinning optimal conditions were established as follows: voltage tension ( $14 \mathrm{kV}$ for PBAT and $18 \mathrm{kV}$ for PBAT/CNTs), $10 \mathrm{~cm}$ as needle-collector distance, solution flow rate of $0.3 \mathrm{~mL} \mathrm{~h}^{-1}$, controlled temperature $\left(21-23^{\circ} \mathrm{C}\right)$ and humidity (44-54\%).

\subsection{Nanocomposite characterization}

ATR-FTIR (Attenuated Total Reflectance Fourier Transform Infrared Spectroscopy) was carried out in a Perkin-Elmer Spotlight 400 FTIR Imaging System and data were collected in the range of $4000-600 \mathrm{~cm}^{-1}$ in absorbance mode.

FE-SEM (Field Emission Scanning Electronic Microscopy) was performed using a Philips XL-30 FEG SEM. Prior to analysis, the samples were coated with a thin layer of gold using a sputter-coat system.

TEM (Transmission Electronic Microscopy) analysis was carried out using a Philips CM120 TEM operated at $120 \mathrm{kV}$. The samples were electrospun directly onto Cooper TEM grids ( 300 mesh) during $3 \mathrm{~s}$ of exposition during electrospinning experiment.

The dynamic contact angle between a deionized water drop and the surface of the nanocomposites was measured. A Krüss contact angle device (Model DSA100) equipped with a recording system was used. Briefly, a single drop of deionized water was deposited on the surface of the nanocomposites (fixed on Teflon substrates) and measurements of the angle between the interface were taken in different times $(0-2400 \mathrm{~s})$. All measurements were carried out in a controlled humidified atmosphere ( 60\%).

The tensile tests were performed in a TA instruments model Q800 operating in tension film mode $\left(25^{\circ} \mathrm{C}\right)$. Samples with fixed geometry (6.4 $\mathrm{mm}$ in width and $5 \mathrm{~mm}$ in gauge length) were strained at a constant rate of $1 \mathrm{~N} \mathrm{~min}^{-1}$ until $18 \mathrm{~N}$ or failure. For each sample, at least five specimens were tested.
DSC (Differential Scanning Calorimetry) measurements were carried out in a calorimetric module Q10 (TA instruments, USA), using sealed aluminum pans, a heating rate of $10{ }^{\circ} \mathrm{C} \mathrm{min}{ }^{-1}$ from -60 to $200{ }^{\circ} \mathrm{C}$, under nitrogen atmosphere (flow rate of $50 \mathrm{~mL} \mathrm{~min}^{-1}$ ). The samples weight ranged from 8 to $10 \mathrm{mg}$. In order to determine the degree of crystallinity $(X c)$ of the samples, the following equation was used:

$X c=\left(\Delta H_{m} / \Delta H_{m}^{o} \varphi_{m}\right) \times 100$

where $\Delta H_{m}$ corresponded to the heat of fusion of the endothermic peak of fusion, $\Delta H_{m}^{o}$ was the heat of fusion for the $100 \%$ crystalline PBAT and $\varphi_{m}$ was the weight fraction of polymeric matrix in the nanocomposite.

\subsubsection{Biological assays}

All samples were placed into well plates and sterilized in absolute ethanol under ultraviolet lamp for $6 \mathrm{~h}$, followed by immersion in $10 \mathrm{~mL}$ of Dulbecco's Modified Eagle's Medium (DMEM, Sigma Aldrich) for $24 \mathrm{~h}$, in accordance with ISO-10993-5.

Culture cells were conducted with MG63 osteoblast-like cells (Cambrex Bio Science Walkersville, Inc.), which were cultured in aModified Eagle's Medium (Gibco-Life Technologies, NY, USA) containing $10 \%$ fetal bovine serum (Gibco), $100\left[1 \mathrm{~g} \mathrm{~mL}^{-1}\right]$ streptomycin (Gibco) and $100\left[1 \mathrm{~g} \mathrm{~mL}^{-1}\right]$ penicillin (Gibco) at $37^{\circ} \mathrm{C}$ in a humidified atmosphere of $5 \%(v / v) \mathrm{CO}_{2}$. The cell culture medium was changed every 3 days. A progression of cultures was examined by phase contrast microscopy (Model Axiovert 40C, Carl Zeiss Microscopy GmbH, Jena, Germany). Cells were used from the second to the third passage in all experiments with $0.25 \%$ trypsin (Gibco) plus 0.02\% EDTA (Sigma, St. Louis, MO, USA). Cell counting was performed by obtaining cell pellets and counting for total cell numbers using a standard hemocytometer (Optik Labor, Lancing, UK). After counting, cells were seeded in 24well plates at 20.000 cells/well on top of each sample. As control, cells were grown onto culture plate (TCP), and the other groups assessment were PBAT samples, PBAT/0.1\%CNTs and PBAT/0.5\%CNTs samples, for all in vitro analysis.

After 24 h, 3 days and 7 days of culture cell, the viable cells on the samples were assessed quantitatively using the MTT [3-(4,5-dimethylthiazol-2-yl)-2,5-diphenyltetrazolium bromide] assay according to the manufacturer instructions (Sigma). MTT assay is currently used to assess cell proliferation since the optical density (OD) values can provide indicators of the cell growth on biomaterials. The MTT solution was added to the cells and incubated at $37^{\circ} \mathrm{C}$ for $4 \mathrm{~h}$ to form purple formazan crystals [46]. Afterwards, the supernatant was removed and the samples were washed with PBS, followed by the addition of $1 \mathrm{~mL}$ of isopropanol acid ( $0.04 \mathrm{M} \mathrm{HCl}$ in isopropyl alcohol) to each well to solubilize the formazan crystals. The solution was transferred to a 96-well plate, and colorimetric analysis was performed for each well. The OD was measured at $570 \mathrm{~nm}$ in an EL808IU spectrophotometer (Biotek Instruments, Winooski, VT, USA) using a reference wavelength of $650 \mathrm{~nm}$. The data was expressed as OD (percentage normalized by the control sample). All samples experiments were performed in triplicate.

The cellular adhesion was further evaluated by FE-SEM at 1 day and 3 days.

ALP activity was evaluated after cell incubation for 5 days by the hydrolysis of thymolphthalein monophosphate substrate (Labtest Diagnóstica, Belo Horizonte, BR) in accordance with the manufacturer's recommendations. Initially, the medium was discarded, and the plates were washed twice with PBS. After, the cells were lysates with $2 \mathrm{~mL}$ of $0.1 \%$ sodium lauryl sulfate (Sigma). $50 \mu \mathrm{L}$ lysates obtained from each well was added to solution containing $50 \mu \mathrm{L}$ of thymolphthalein monophosphate with $0.5 \mathrm{~mL}$ of $0.3 \mathrm{M}$ diethanolamine buffer at $37^{\circ} \mathrm{C}$. It was added also $2 \mathrm{~mL}$ of $0.09 \mathrm{M} \mathrm{Na}_{2} \mathrm{CO}_{3}$ and $0.25 \mathrm{M} \mathrm{NaOH}$ for color development. Following, $50 \mu \mathrm{L}$ were collected and added in triplicate, into a 96-well plate, and the absorbance was measured by spectrophotometer (Shimadzu Europa GmbH UV 1203) at $590 \mathrm{~nm}$. The ALP activity was 
Table 1

Chloroform/DMF rations and their respective values of density and surface tension; solutions containing PBAT or PBAT/CNTs in chloroform/DMF (60:40) and their respective values of density, surface tension and dynamic viscosity.

\begin{tabular}{|c|c|c|c|}
\hline $\begin{array}{l}\text { Chloroform/DMF } \\
\text { ratio }\end{array}$ & $\begin{array}{l}\text { Density } \\
\left(\mathrm{g} \mathrm{mL}^{-1}\right)\end{array}$ & $\begin{array}{l}\text { Surface tension } \\
\left(\mathrm{mN} \mathrm{m}^{-1}\right)\end{array}$ & $\begin{array}{l}\text { Dynamic viscosity } \\
\left(\mathrm{mPa} \mathrm{s}^{-1}\right)\end{array}$ \\
\hline Solution* & $\begin{array}{l}\text { Density } \\
\left(\mathrm{g} \mathrm{mL}^{-1}\right)\end{array}$ & $\begin{array}{l}\text { Surface tension } \\
\left(\mathrm{mN} \mathrm{m}^{-1}\right)\end{array}$ & $\begin{array}{l}\text { Dynamic viscosity } \\
\left(\mathrm{mPa} \mathrm{s}^{-1}\right)\end{array}$ \\
\hline $50 / 50$ & 1.2 & 28.7 & - \\
\hline $60 / 40$ & 1.3 & 10.6 & - \\
\hline $75 / 25$ & 1.4 & 18.5 & - \\
\hline $85 / 15$ & 1.4 & 17.1 & - \\
\hline PBAT & 1.3 & 16.2 & 47.3 \\
\hline PBAT/0.1\%CNTs & 1.3 & 14.6 & 77.3 \\
\hline PBAT/0.5\%CNTs & 1.3 & 21.0 & 177.2 \\
\hline
\end{tabular}

* Solutions were prepared using chloroform/DMF at 60/40 ratio.

standardized using total protein level, and the values were presented in $\mu \mathrm{mol}$ of thymolphthalein $/ \mathrm{h} / \mathrm{mg}$ protein $/ \mathrm{mL}$.

After 14 days in culture, wells were washed three times with Hank's solution (Sigma) at $37{ }^{\circ} \mathrm{C}$, and fixed with $70 \%$ ethanol for $1 \mathrm{~h}$ at $4{ }^{\circ} \mathrm{C}$. After fixation, the wells were washed twice with PBS and stained for $1 \mathrm{~h}$ with $2 \%$ Alizarin red S (Sigma), $\mathrm{pH}$ 4.2. To quantify the mineralized nodules was used to the method previously described by Gregory, Grady Gunn, Peister and Prockop [47]. The color intensity, which was proportional to the calcium deposition, was measured at a wavelength of $405 \mathrm{~nm}$.

The above experiments were repeated four times. All in vitro assays results were expressed as mean \pm standard deviations. Statistical analyses were performed using GraphPad Prism software (GraphPad Software version 5.0, San Diego, CA, USA). Statistical comparisons were carried out via one-way ANOVA for ALP activity and mineralized nodules and multiple comparisons Tukey's test to determine any significant differences between each group. For MTT statistical comparisons a twoway ANOVA followed by Bonferroni test was employed. Differences were considered statistically significant at $\mathrm{p}<0.05$.

\section{Results and discussion}

\subsection{Preparation of the PBAT/CNTs nanocomposites}

We studied different ratios of chloroform/DMF, considering their density and surface tension, in order to choose the best condition for
PBAT/CNTs dissolution and posterior electrospinning. The results are depicted in Table 1.

Table 1 shows different ratios of chloroform/DMF led to solutions with similar density values ( 1.3 and $\left.1.4 \mathrm{~g} \mathrm{~mL}^{-1}\right)$. However, the solutions differed significantly regarding their surface tension, while 50/50 (chloroform/DMF) presented the highest value $\left(28.7 \mathrm{mN} \mathrm{m}^{-1}\right)$, the $60 / 40$ (chloroform/DMF) presented the lowest $\left(10.6 \mathrm{mN} \mathrm{m}^{-1}\right.$ ). In order to keep the Taylor's cone stable, solutions with low surface tension are usually desirable for electrospinning, which directed our choice to use the 60/40 system for PBAT/CNTs dissolution and posterior electrospinning.

Table 1 also shows the density, surface tension and dynamic viscosity values for the solutions prepared from PBAT and PBAT/CNTs in chloroform/DMF (60:40). No difference was observed regarding the density values, whereas the dynamic viscosity increased with the addition of CNTs, as expected. At the highest content of CNTs ( $0.5 \mathrm{wt} . \%)$, the surface tension reached its high value $\left(21.0 \mathrm{mN} \mathrm{m}^{-1}\right)$.

\subsection{Nanocomposite characterization}

\subsubsection{Fourier transform infrared spectroscopy (FTIR)}

Fig. 2 shows the FTIR spectra of the electrospun PBAT and electrospun PBAT/CNTs nanocomposites.

The FTIR spectra of the electrospun PBAT [Fig. 2-(a)] and PBAT/CNTs nanocomposites [Fig. 2-(b and c)] exhibited the characteristics peaks of the polyester, PBAT, as following [48,49]: $2950 \mathrm{~cm}^{-1}$, asymmetric stretching vibration of $\mathrm{CH}_{2}$ groups; $1710 \mathrm{~cm}^{-1}$, stretching vibration of $\mathrm{C}-0$; characteristic stretching of phenylene group at $1456 \mathrm{~cm}^{-1}$, $1505 \mathrm{~cm}^{-1}$, and $1580 \mathrm{~cm}^{-1} ; 1410 \mathrm{~cm}^{-1}$ and $1395 \mathrm{~cm}^{-1}$, trans- $\mathrm{CH}_{2^{-}}$ plane bending vibration; $1275 \mathrm{~cm}^{-1}$, symmetric stretching vibration of C-O; $1100 \mathrm{~cm}^{-1}$, C-O left-right symmetric stretching vibration absorption; $1016 \mathrm{~cm}^{-1} ; 731 \mathrm{~cm}^{-1}$, bending vibration absorption of $\mathrm{CH}-$ plane of the phenylene ring.

The low contents of sMWCNT ( 0.1 and 0.5 wt.\%) did not promote any significant modification in the FTIR spectra.

3.2.2. Morphologic analysis by field emission scanning electronic microscopy (FE-SEM) and transmission electronic microscopy (TEM)

Fig. 3 shows the FE-SEM micrographs for the electrospun PBAT and electrospun PBAT/CNTs nanocomposites.

From the SEM micrographs (Fig. 3), it can be observed the presence of ultrathin fibers $(100<$ diameters $<1000 \mathrm{~nm})$ and beads along the surface of all samples. The presence of sMWCNT [Fig. 3(b, c)] clearly

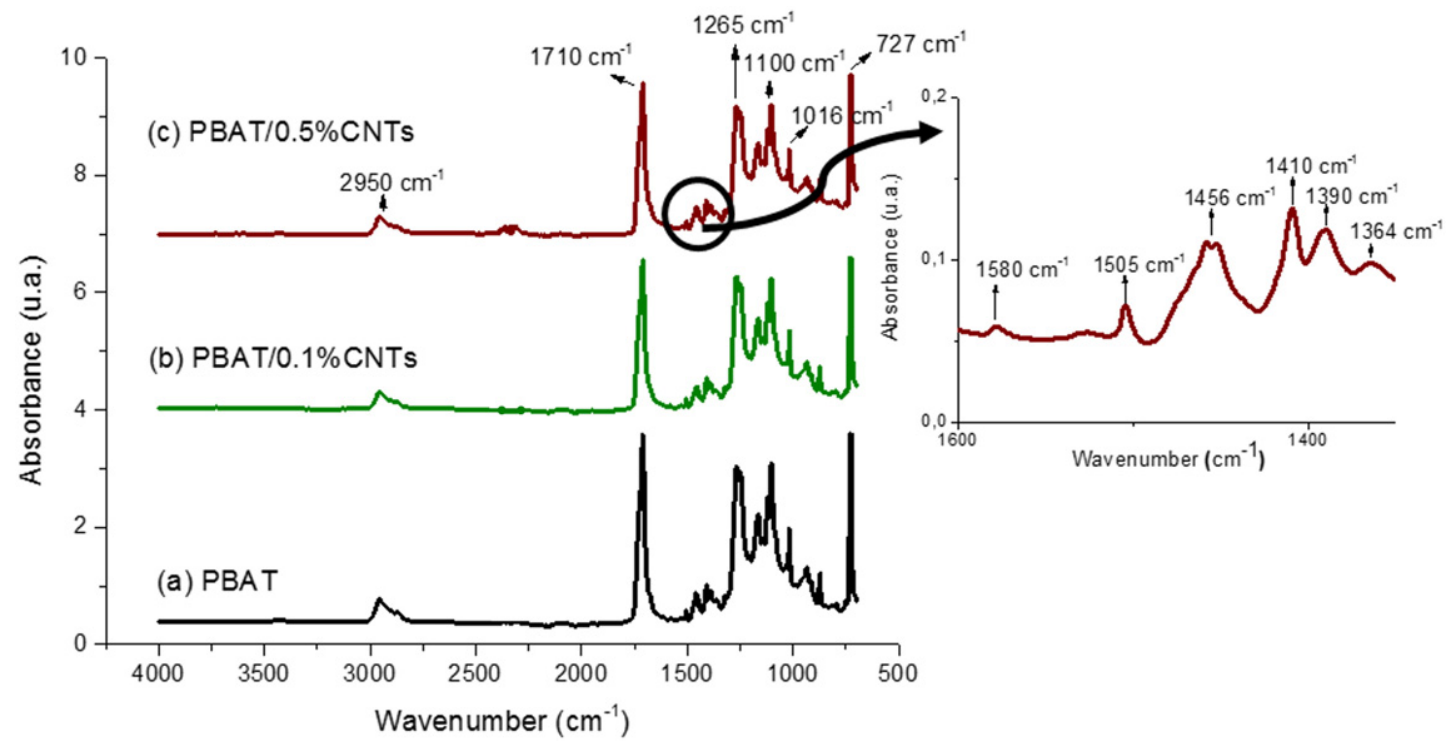

Fig. 2. FTIR spectra of (a) PBAT; (b) PBAT/0.1\%CNTs; (c) PBAT/0.5\%CNTs. 

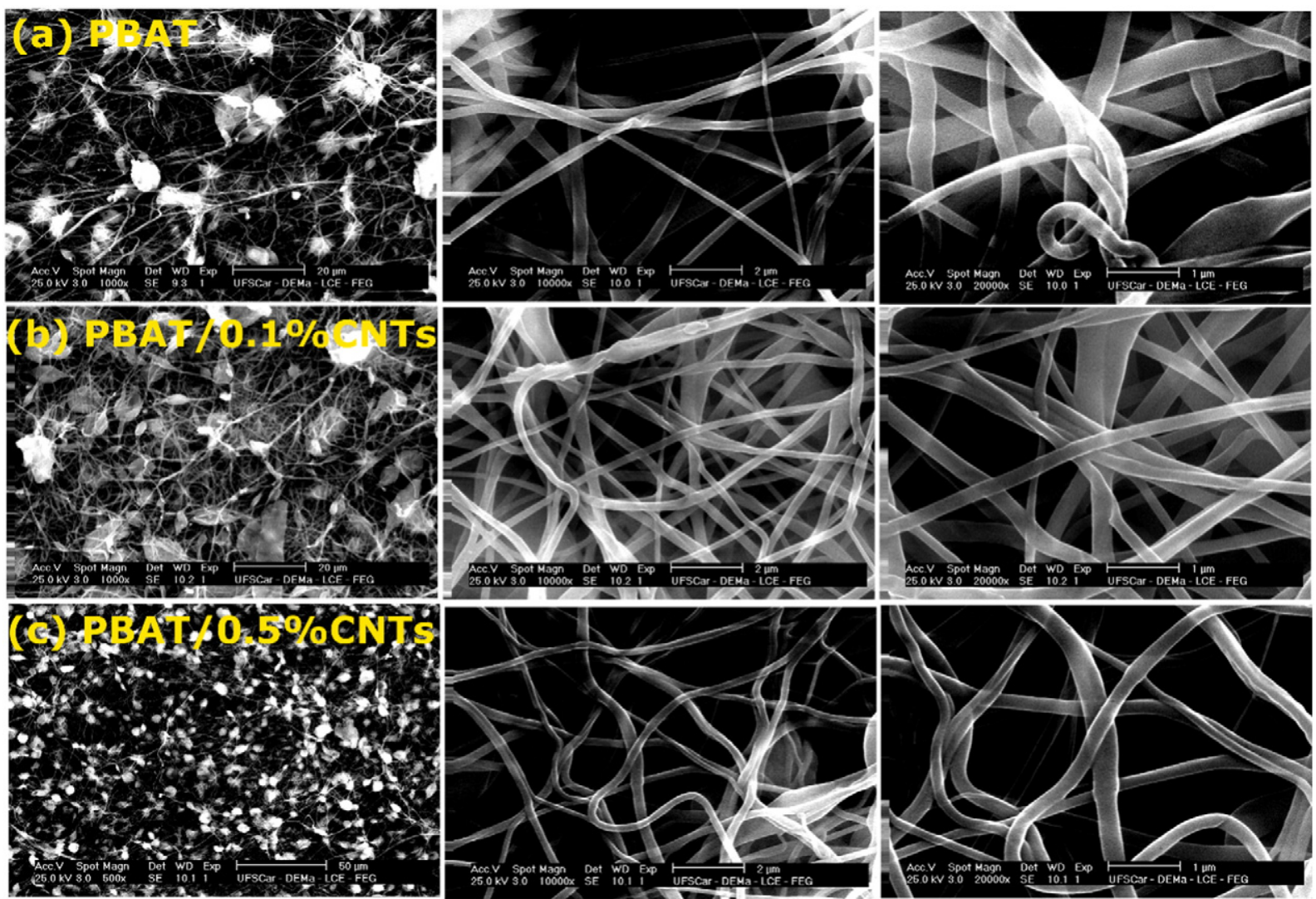

Fig. 3. FE-SEM micrographs of (a) PBAT; (b) PBAT/0.1\%CNTs; (c) PBAT/0.5\%CNTs nanocomposites.

increased the presence of beads, which can be explained by the increase of surface tension and viscosity of the solutions (Table 1). In the meanwhile, reductions in the average diameter of the fibers from $497 \pm$ $148 \mathrm{~nm}$ (PBAT) to $272 \pm 79 \mathrm{~nm}$ (PBAT/0.1\%CNTs) and $250 \pm 52 \mathrm{~nm}$ (PBAT/0.5\%CNTs) were observed. These reductions may be attributed to the increase in the electrical conductivity and consequent increase in the neat charge density in the jet due to the presence of sMWCNT. This increase in the neat charge density is also related to responsible by the decrease in the average diameter of the beads and their fusiform aspect (Fig. 3) [50]. Regarding the diameters' distribution, Fig. 4 shows the histograms of diameter distribution for PBAT and PBAT/CNTs electrospun fibers.

As it can be observed in Fig. 4, the presence of sMWCNT led not only to smaller fiber' average diameters, but it also generated narrower distributions. This fact is also supported by comparing the standard deviations of PBAT $( \pm 148 \mathrm{~nm})$ to PBAT/0.1\%CNTs and PBAT/0.5\%CNTs ( $\pm 79 \mathrm{~nm}$ and $\pm 52 \mathrm{~nm}$, respectively). As previously mentioned, the presence of sMWCNT promotes an increase of neat charges in the solutions, which in turn may be responsible to generate more stable electrospinning jets and consequent more homogeneous electrospun fibers. Saligheh, Forouharshad, Arasteh, Eslami-Farsani, Khajavi and Yadollah Roudbari [27] reporting on the electrospinning of poly (butylene terephthalate) (PBT)/MWCNT composites also observed thinner fibers and narrower distributions with the addition of MWCNT (0.52.0 wt.\%).

The internal structural details of the PBAT/CNTs nanocomposites were further investigated by TEM (Fig. 5).

The low concentrations of sMWCNT (0.1-0.5 wt.\%) in the matrix hampered their proper visualization by TEM, although it was possible to observe the absence of agglomerate-like regions, suggesting that homogeneous distributions were achieved. In Fig. 5(b), the TEM micrograph clearly showed the embedded sMWCNT were entangled (indicated by an arrow).

\subsubsection{Contact angle measurements}

The characterization of the hydrophilic/hydrophobic properties of a material is essential to get a deep comprehension of its potential applications. When applications in the biomedical field are considered, such as in tissue engineering, it is extremely expected the use of a material with good wettability/hydrophilicity. Thus, in order to evaluate the
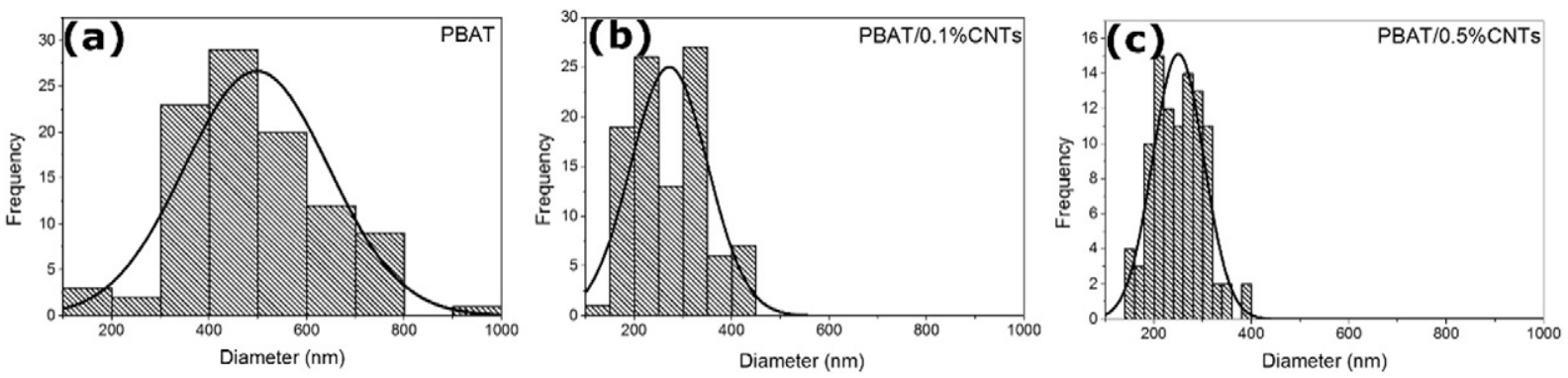

Fig. 4. Histograms of diameter distribution for (a) PBAT and nanocomposites (b) PBAT/0.1\%CNTs and (c) PBAT/0.5\%CNTs based on 100 measures (SEM micrographs). 

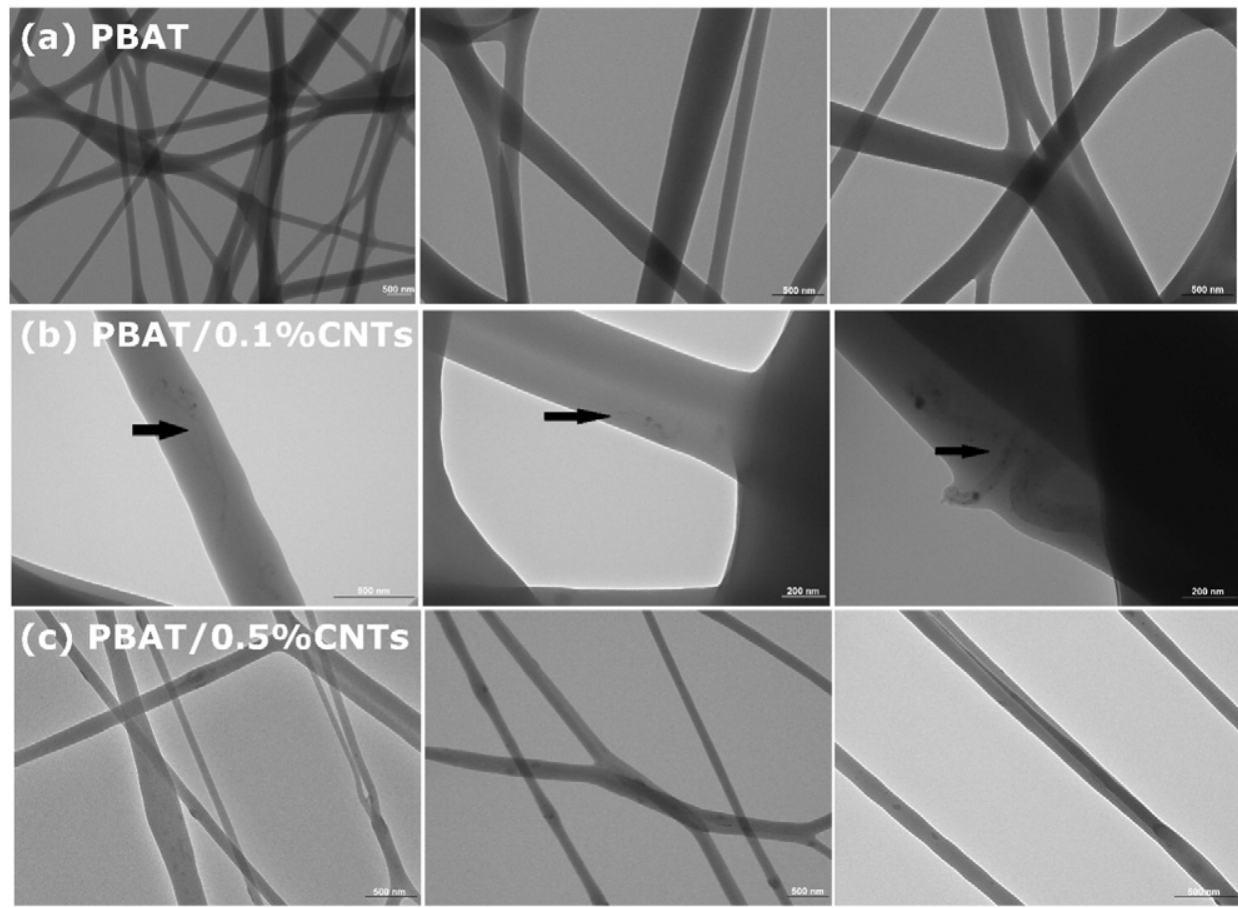

Fig. 5. TEM micrographs of (a) PBAT; (b) PBAT/0.1\%CNTs; (c) PBAT/0.5\%CNTs nanocomposites.

effects of SMWCNT on the surface properties of the electrospun nanocomposites, the water contact angle was measured for PBAT and for the nanocomposite with the highest sMWCNT content (PBAT/ $0.5 \%$ CNTs) (Fig. 6).

From the curves of contact angle (Fig. 6 ), the values of advancing contact angle (ACA, maximum angle) were $113^{\circ}$ and $137^{\circ}$ for PBAT and PBAT $/ 0.5 \%$ CNTs, respectively. The high values of ACA pointed out the hydrophobic character of these materials. It is well-known that the topography of the electrospun mat plays an important role in the final wetting behavior. Several studies report that surfaces with beads are more hydrophobic than those that contain only fibers [51,52]. Thus, the generation of more beaded surfaces with the addition of sMWCNT (Fig. 3) may have contributed to the higher value of ACA. In addition, the expected interactions between the sMWCNT polar groups ( $\mathrm{COH}, \mathrm{OH}, \mathrm{C}=\mathrm{O}$, and $\mathrm{COOH}$ ) with the polar sites of the polymer chains may be also responsible for reducing the available polar sites able to interact with the water molecules.

\subsubsection{Thermal properties}

Fig. 7 shows the DSC thermograms of electrospun PBAT and electrospun PBAT/CNTs nanocomposites.

It can be observed from the DSC curves that the addition of SMWCNT had no influence on the glass transition temperature $\left(\mathrm{T}_{g}\right)$, and a $\mathrm{T}_{g}$ of $-31.5^{\circ} \mathrm{C}$ was observed for all electrospun samples. Regarding the melting temperature $\left(\mathrm{T}_{m}\right)$, electrospun PBAT and PBAT/0.1\%CNTs nanocomposite presented a $\mathrm{T}_{m}$ of $114.9{ }^{\circ} \mathrm{C}$ while a slight shift was observed at the highest sMWCNT concentration (PBAT $/ 0.5 \% \mathrm{CNTs}, 117.8^{\circ} \mathrm{C}$ ). For all DSC curves, two small endothermic peaks were observed in the region of $50-60{ }^{\circ} \mathrm{C}$ and $150-160{ }^{\circ} \mathrm{C}$, which can be attributed to the vaporization of small amounts of residual solvent (chloroform and DMF, respectively).

Based on the melting enthalpy, the degree of crystallinity $(\chi)$ was calculated from the following formula:

$$
\chi=\frac{\Delta H_{m}}{\Delta H_{m 100}}
$$

where $\Delta H_{m}$ was the melting enthalpy of the samples and $\Delta H_{m 100}$ was the melting enthalpy of PBAT in 100\% crystalline form, which is reported to be $114 \mathrm{Jg}^{-1}$ [53].

Electrospun PBAT presented a degree of crystallinity of $19.6 \%$, while the addition of sMWCNT in the smallest content (PBAT/0.1\%CNTs) increased the degree of crystallinity to $29.6 \%$. Conversely, increasing the sMWCNT content (PBAT/0.5\%CNTs) significantly decreased the degree of crystallinity to $11.4 \%$. The increase in crystallinity in the first moment may indicate that the dispersion of sMWCNT in the PBAT matrix
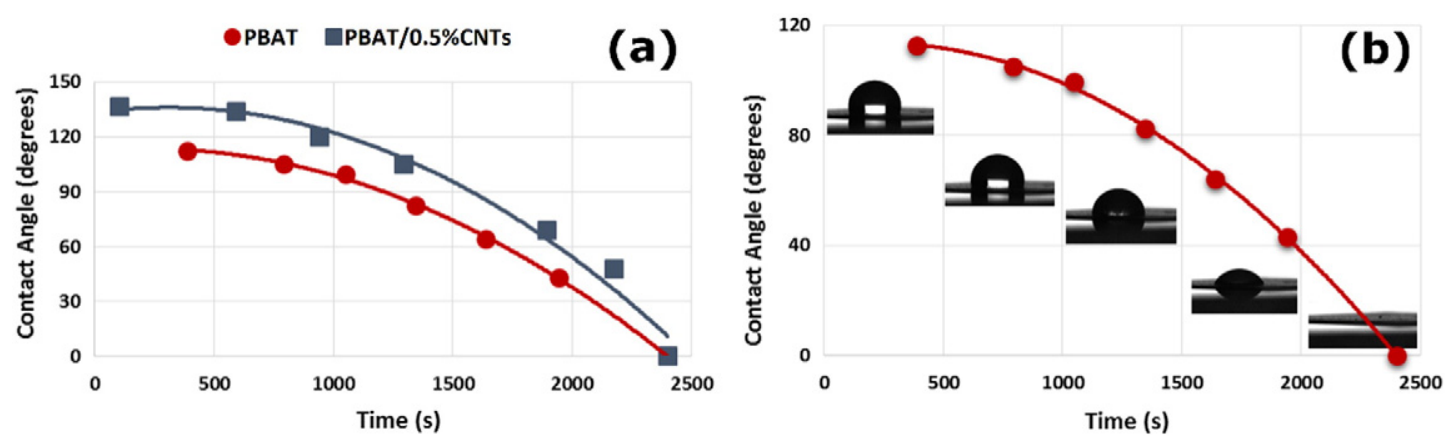

Fig. 6. Contact angle for (a) PBAT and PBAT/0.5\%CNTs; (b) PBAT with snapshots taken at different times. 


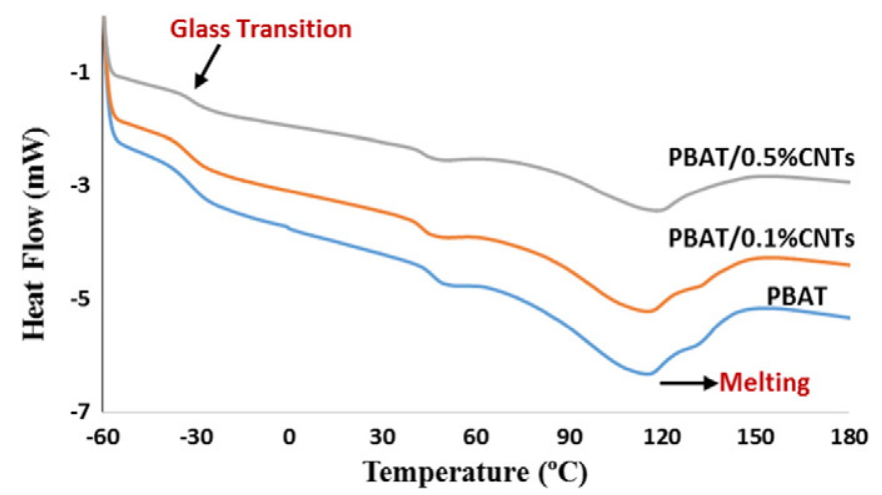

Fig. 7. DSC curves of PBAT and PBAT/CNTs nanocomposites $\left(\mathrm{N}_{2}\right.$ atmosphere at $50 \mathrm{~mL} \mathrm{~min}{ }^{-1}$ and heating rate of $10{ }^{\circ} \mathrm{C} \mathrm{min}^{-1}$ ).

enhanced its crystallization through the occurrence of heterogeneous nucleation. Thus, with the addition of a small sMWCNT content ( $0.1 \%$ CNTs), the mobility of the PBAT macromolecular chains can be enhanced, leading then to higher crystallization rate and degree of crystallinity. Nevertheless, as the sMWCNT content increased ( $0.5 \mathrm{wt} . \%)$, the fillers can block the mobility of the polymer chains and prevent their macromolecular segments to achieve order alignment of crystal lattices [27].

Thermogravimetric analysis (TGA, figures not shown) revealed no significant difference regarding the thermal stability of the samples.

\subsubsection{Tensile properties}

In order to study the effects of sMWCNT on the mechanical properties of the electrospun fibers from PBAT, the tensile strength, elongation at break and young modulus of PBAT and PBAT/CNTs electrospun fibers were evaluated (Fig. 9). Fig. 8 presents typical stress-strain curves for PBAT and PBAT $/ 0.5 \%$ CNTs.

Fig. 9 shows that the addition of sMWCNT gradually increased the strength and stiffness of the electrospun fibers, evidencing the reinforcement effect of the sMWCNT as they constrain the segmental motions of neighboring polymer chains [54]. The tensile strength and Young Modulus increased from 1.3 to $3.58 \mathrm{MPa}$ and from 3.3 to 6.5 MPa, respectively, with the addition of $0.5 \mathrm{wt}$.\% of sMWCNT whereas

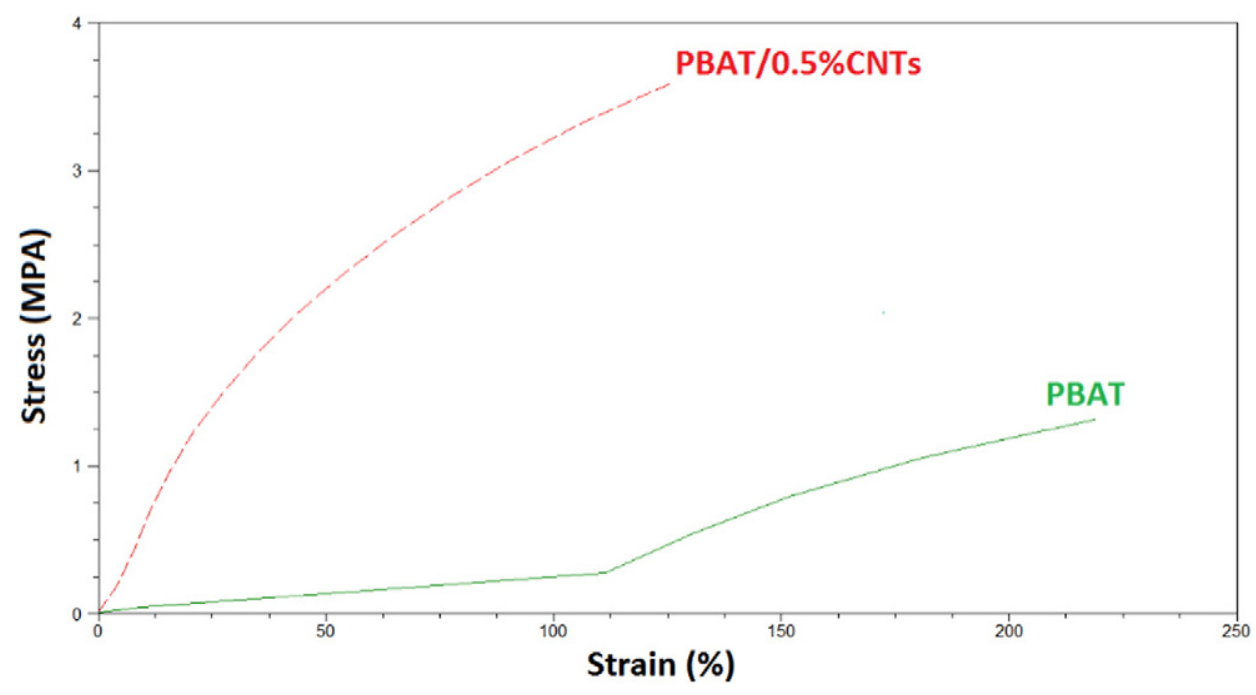

Fig. 8. Stress-strain curves for PBAT and PBAT/0.5\%CNTs.

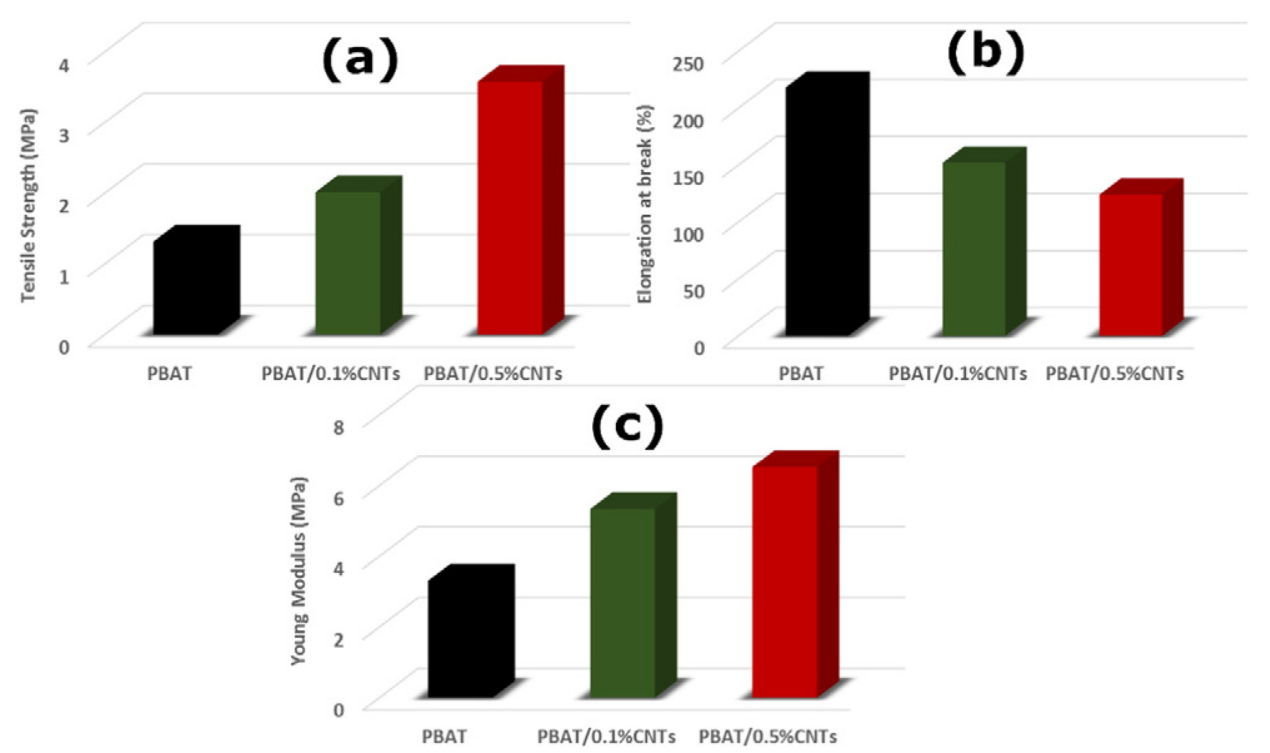

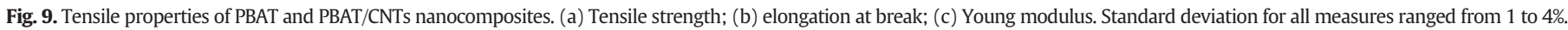




\section{Cellular Cytotoxicity}

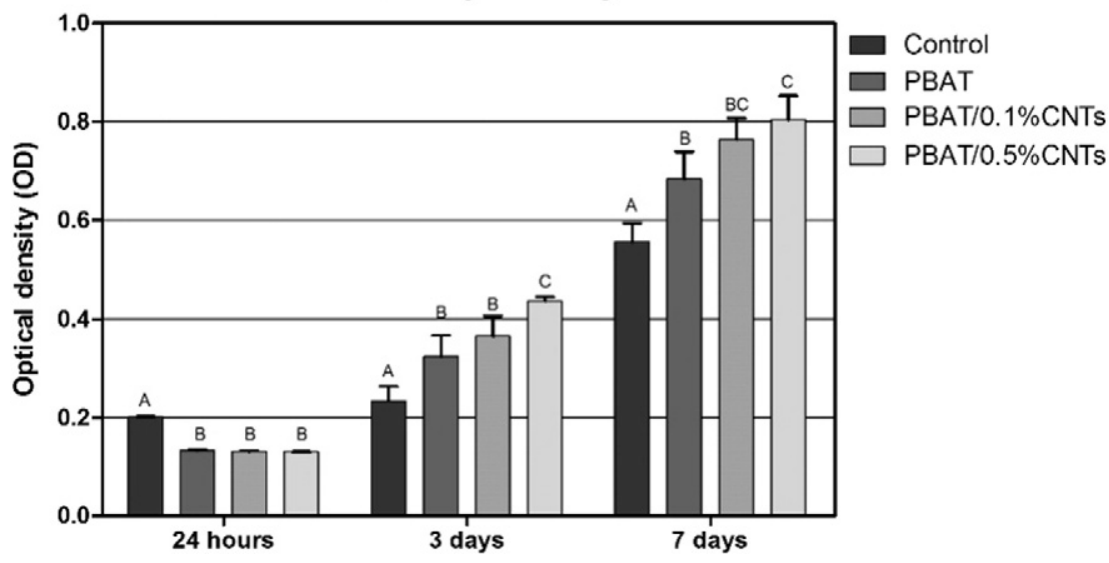

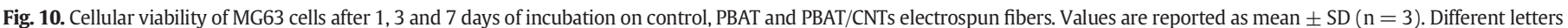
show significant differences for $\mathrm{p}<0.05$.

the elongation at break decreased from 218 to $124 \%$. The increase in the tensile strength and Young modulus with the addition of sMWCNT has been constantly reported. McCullen, Stevens, Roberts, Ojha, Clarke and Gorga [28] reported on the preparation of electrospun mats from poly (ethylene oxide)/MWCNT with enhanced tensile properties. Saligheh, Forouharshad, Arasteh, Eslami-Farsani, Khajavi and Yadollah Roudbari [27] reporting on the reinforcement of PBT matrices with sMWCNT observed that the addition of sMWCNT from 0.5 to $1 \mathrm{wt} . \%$ also increased the tensile strength and modulus, whereas further increasing (2$4 \mathrm{wt} . \%)$ was responsible for lowering these properties.

3.2.5.1. Cell culture. The cell viability of MG63 cells on all samples was monitored within 1 day, 3 days and 7 days of culturing. As depicted in Fig. 10, the OD data showed that the viable cells increased with the time and that there was a significant difference among the samples into each period. At 3 days, the control showed more cells viable with significant difference to the other groups. However, analysis of variance indicated significant differences between the PBAT/0.5\%CNTs samples groups ( $p<0.05$ ), after 3 days and 7 days and the Tukey's post hoc test revealed that OD value for PBAT/0.5\%CNTs was significantly higher than all others groups, except of PBAT/0.1\%CNTs at 7 days.

It is well known that the cytotoxicity of a biomaterial is affected by several factors such as its surface topology, hydrophilicity, among others [6]. We observed that all biomaterials allowed for a greater number of viable cells than the control group, except at $24 \mathrm{~h}$. PBAT/0.5\%CNTs showed better results, indicating that the incorporation of $0.5 \%$ of CNTs increased its biocompatibility. Thus, all samples are viable for biomedical use in accordance with ISO-10993-5.

Fig. 11 shows the FE-SEM micrographs for the evaluation of the MG63 cells adhesion on PBAT and PBAT/CNTs electrospun fibers after 1 and 3 days of incubation. The cells showed ability to interact with all samples and we could identify the presence of longer cytoplasmatic projections of the MG63 cells and a normal cellular morphology, both factors that confirmed the cytocompatibility of all samples within
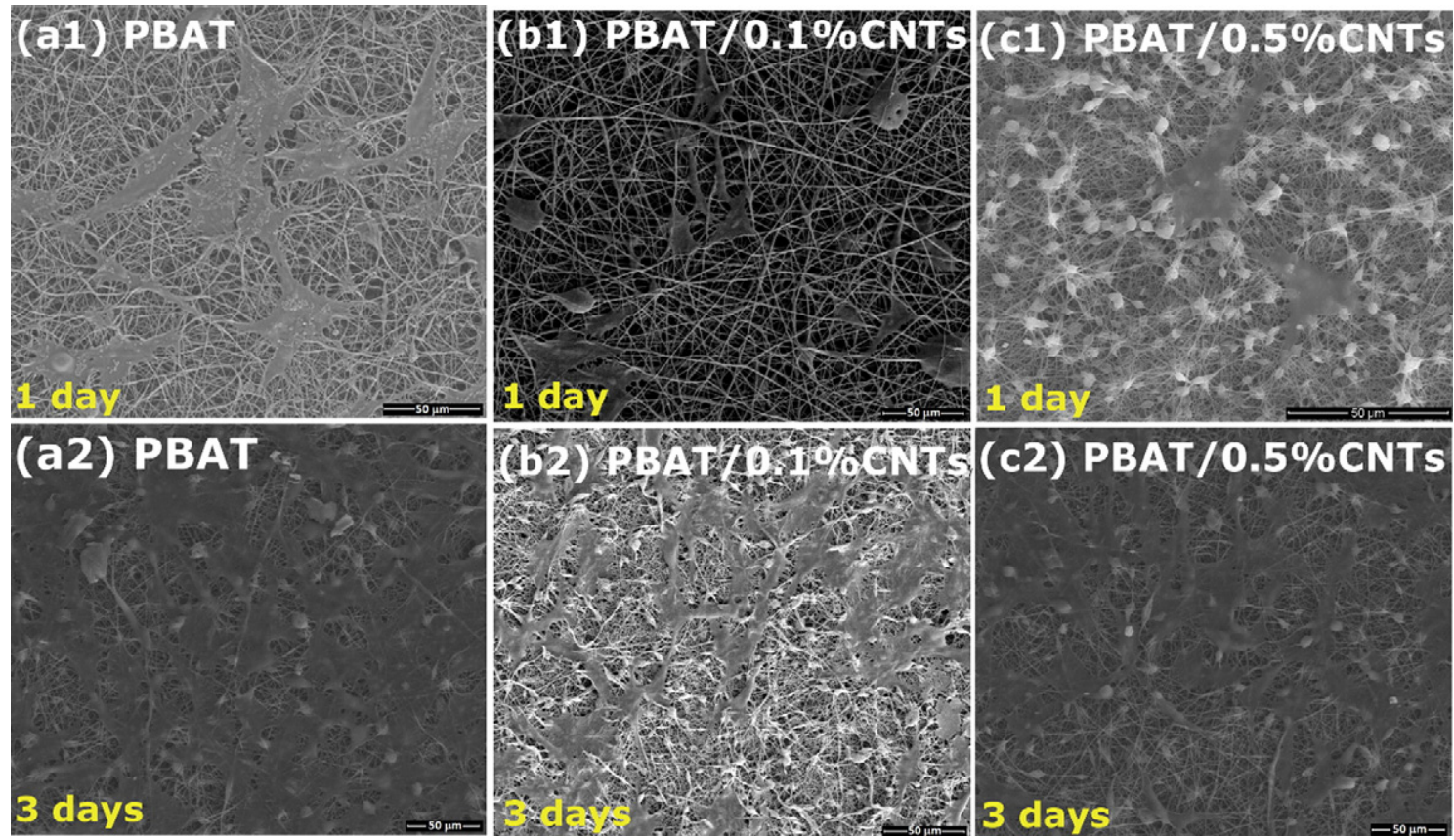

Fig. 11. FE-SEM micrographs of MG63 cells cultivated on PBAT and PBAT/CNTs electrospun fibers after 1 and 3 days of incubation. 

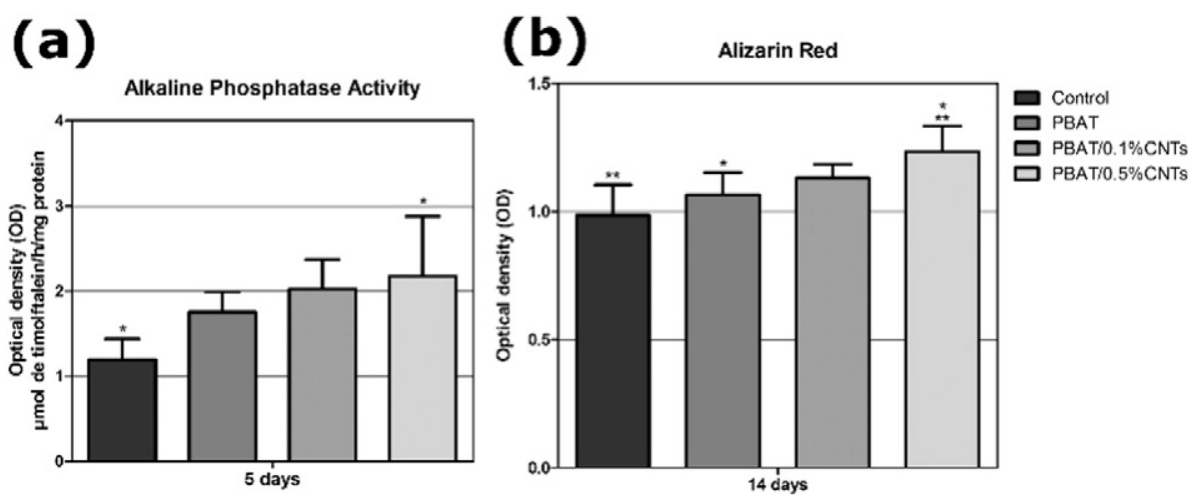

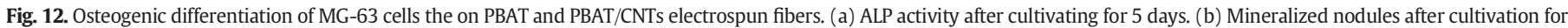
14 days. Values are reported as mean $\pm S D(n=3)$. Different letters show significant differences for $\mathrm{p}<0.05$.

MG63 cells. Fig. 11(a1, b1, c1) shows the initial phase of cell adhesion with cells spreading with no preferential direction, resulting in the formation of a monolayer after 3 days of incubation [Fig. 11(a2, b2, c2)].

ALP activity is known to be an early indicator of osteoblast differentiation and its expression is considered to be a functional parameter in vitro, reflecting the progress of cell differentiation [55]. The biomaterial composition has presented an important role in osteoblastic differentiation $[39,44]$, and here we noted that ALP activity was positively affected by the biomaterial [Fig. 12-(a)]. At 5 days, PBAT/0.5\% CNTs presented the highest ALP value and a significant difference when compared to the control group $(\mathrm{p}<0.05)$.

There is a sequence of cell events that occur with the cells on the biomaterial surfaces. Initially, cells do attachment and proliferation and further differentiate to synthesize collagen and other proteins, inducing their own in vitro mineralization in certain culture medium conditions [56]. Overall, all PBAT groups presented better results than control group. Then we observed that the mineralized matrix formation was influenced by the biomaterial [Fig. 12-(b)], and PBAT/0.5\% CNTs presented the higher values $(\mathrm{p}<0.05)$ when compared to control group and PBAT.

Summary, the MG-63 cells cultured on PBAT/CNTs showed more viable cell and ALP activity than the control group and PBAT, in accordance with previous works $[39,57]$. In addition, a significant increase in the amount of mineralized matrix was detected.

\section{Conclusions}

Electrospun fibers from PBAT and PBAT/superhydrophilic MWCNT (sMWCNT) solutions were successfully produced and characterized by a wide range of techniques. The fibers showed porous and interconnected fibers with diameters that ranged from $250 \pm 52 \mathrm{~nm}$ (PBAT/ $0.5 \% \mathrm{CNTs}$ ) to $497 \pm 148 \mathrm{~nm}$ (PBAT). The presence of sMWCNT reinforced the PBAT matrix, increasing its tensile strength (from 1.3 to 3.6 MPa with addition of $0.5 \mathrm{wt} . \%$ of sMWCNT) and leading to lower elongations at break. All samples showed cytocompatibility with MG63 cells and only a slight reduction of cell viability was observed when sMWCNT were present. MG-63 cells osteogenic differentiation (measured by ALP activity) showed that mineralized nodules formation was increased in PBAT/0.5\%CNTs when compared to control group (cells). This study opens the possibility for producing electrospun PBAT scaffolds with enhanced mechanical properties and potential of application in tissue engineering and bone regeneration.

\section{Acknowledgments}

The authors would like to thank National Council for Scientific and Technological Development (CNPq, 474090/2013-2), Sao Paulo Research Foundation (FAPESP, 2011/17877-7, 2011/20345-7 and 2015/01259-3), Brazilian Innovation Agency (FINEP) and Coordination for the Improvement of Higher Education Personnel (CAPES, 88887.095044/2015-00) for financial support. B. V. M. R. would also like to thank FAPESP for the postdoctoral fellowship (2015/08523-8).

\section{References}

[1] R.J. O'Keefe, J. Mao, Bone tissue engineering and regeneration: from discovery to the clinic-an overview, Tissue Eng. B Rev. 17 (2011) 389-392.

[2] A.J. Salgado, O.P. Coutinho, R.L. Reis, Bone tissue engineering: state of the art and future trends, Macromol. Biosci. 4 (2004) 743-765.

[3] A. Oryan, S. Alidadi, A. Moshiri, N. Maffulli, Bone regenerative medicine: classic options, novel strategies, and future directions, J. Orthop. Surg. Res. 9 (2014).

[4] H.Y. Mi, X. Jing, L.S. Turng, Fabrication of porous synthetic polymer scaffolds for tissue engineering, J. Cell. Plast. 51 (2014) 165-196.

[5] D.W. Hutmacher, Scaffold design and fabrication technologies for engineering tissues - state of the art and future perspectives, J. Biomater. Sci. Polym. Ed. 12 (2001) 107-124.

[6] G.C. Ingavle, J.K. Leach, Advancements in electrospinning of polymeric nanofibrous scaffolds for tissue engineering, Tissue Eng. B Rev. 20 (2014) 277-293.

[7] S. Khorshidi, A. Solouk, H. Mirzadeh, S. Mazinani, J.M. Lagaron, S. Sharifi, S. Ramakrishna, A review of key challenges of electrospun scaffolds for tissueengineering applications, J. Tissue Eng. Regen. Med. (2015)http://dx.doi.org/10. 1002/term.1978.

[8] L. Weng, J. Xie, Smart electrospun nanofibers for controlled drug release: recent advances and new perspectives, Curr. Pharm. Des. 21 (2015) 1944-1959.

[9] J.S. Choi, H.S. Kim, H.S. Yoo, Electrospinning strategies of drug-incorporated nanofibrous mats for wound recovery, Drug Deliv. Transl. Res. 5 (2015) 137-145.

[10] S. Kaur, S. Sundarrajan, D. Rana, R. Sridhar, R. Gopal, T. Matsuura, S. Ramakrishna, Review: the characterization of electrospun nanofibrous liquid filtration membranes, J. Mater. Sci. 49 (2014) 6143-6159.

[11] B.D. Ulery, L.S. Nair, C.T. Laurencin, Biomedical applications of biodegradable polymers, J. Polym. Sci. B Polym. Phys. 49 (2011) 832-864

[12] M. Abedalwafa, F. Wang, L. Wang, C. Li, Biodegradable poly-epsilon-caprolactone (PCL) for tissue engineering applications: a review, Rev. Adv. Mater. Sci. 34 (2013) 123-140.

[13] M. Shah Mohammadi, M.N. Bureau, S.N. Nazhat, Polylactic acid (PLA) biomedical foams for tissue engineering, Biomed. Foams Tissue Eng. Appl. (2014) 313-334.

[14] M. Okamoto, B. John, Synthetic biopolymer nanocomposites for tissue engineering scaffolds, Prog. Polym. Sci. 38 (2013) 1487-1503.

[15] K. Fukushima, M.H. Wu, S. Bocchini, A. Rasyida, M.C. Yang, PBAT based nanocomposites for medical and industrial applications, Mater. Sci. Eng. C 32 (2012) 1331-1351.

[16] L. Jiang, M.P. Wolcott, J. Zhang, Study of biodegradable polylactide/poly(butylene adipate-co-terephthalate) blends, Biomacromolecules 7 (2006) 199-207.

[17] D. Wei, H. Wang, H. Xiao, A. Zheng, Y. Yang, Morphology and mechanical properties of poly(butylene adipate-co-terephthalate)/potato starch blends in the presence of synthesized reactive compatibilizer or modified poly(butylene adipate-coterephthalate), Carbohydr. Polym. 123 (2015) 275-282.

[18] J.H. Kim, J.C. Lee, G.H. Kim, Study on poly(butylene adipate-co-terephthalate)/starch composites with polymeric methylenediphenyl diisocyanate, J. Appl. Polym. Sci. 132 (2015).

[19] C.-S. Wu, Antibacterial and static dissipating composites of poly(butylene adipateco-terephthalate) and multi-walled carbon nanotubes, Carbon 47 (2009) 3091-3098.

[20] T. Mukherjee, M. Czaka, N. Kao, R.K. Gupta, H.J. Choi, S. Bhattacharya, Dispersion study of nanofibrillated cellulose based poly(butylene adipate-co-terephthalate) composites, Carbohydr. Polym. 102 (2014) 537-542.

[21] W.A. Ribeiro Neto, A.C.C. De Paula, T.M.M. Martins, A.M. Goes, L. Averous, G. Schlatter, R.E. Suman Bretas, Poly (butylene adipate-co-terephthalate)/hydroxyapatite composite structures for bone tissue recovery, Polym. Degrad. Stab. 120 (2015) 61-69.

[22] M. Paradise, T. Goswami, Carbon nanotubes - production and industrial applications, Mater. Des. 28 (2007) 1477-1489. 
[23] A. Aqel, K.M.M.A. El-Nour, R.A.A. Ammar, A. Al-Warthan, Carbon nanotubes, science and technology part (I) structure, synthesis and characterisation, Arab. J. Chem. 5 (2012) 1-23.

[24] V. Mittal, Polymer Nanotubes Nanocomposites: Synthesis, Properties and Applications, Second edition, 2014.

[25] M. Moniruzzaman, K.I. Winey, Polymer nanocomposites containing carbon nanotubes, Macromolecules 39 (2006) 5194-5205.

[26] Y. Liu, S. Kumar, Polymer/carbon nanotube nano composite fibers-a review, ACS Appl. Mater. Interfaces 6 (2014) 6069-6087.

[27] O. Saligheh, M. Forouharshad, R. Arasteh, R. Eslami-Farsani, R. Khajavi, B. Yadollah Roudbari, The effect of multi-walled carbon nanotubes on morphology, crystallinity and mechanical properties of PBT/MWCNT composite nanofibers, J. Polym. Res. 20 (2013) 1-6.

[28] S.D. McCullen, D.R. Stevens, W.A. Roberts, S.S. Ojha, L.I. Clarke, R.E. Gorga, Morphological, electrical, and mechanical characterization of electrospun nanofiber mats containing multiwalled carbon nanotubes, Macromolecules 40 (2007) 997-1003.

[29] A.O. Lobo, M.A.F. Corat, E.F. Antunes, M.B.S. Palma, C. Pacheco-Soares, E.E. Garcia, E.J. Corat, An evaluation of cell proliferation and adhesion on vertically-aligned multiwalled carbon nanotube films, Carbon 48 (2010) 245-254

[30] D.A. Stout, Recent advancements in carbon nanofiber and carbon nanotube applications in drug delivery and tissue engineering, Curr. Pharm. Des. 21 (2015) 2037-2044.

[31] Y. Che, H. Chen, H. Gui, J. Liu, B. Liu, C. Zhou, Review of carbon nanotube nanoelectronics and macroelectronics, Semicond. Sci. Technol. 29 (2014).

[32] G. Jia, H. Wang, L. Yan, X. Wang, R. Pei, T. Yan, Y. Zhao, X. Guo, Cytotoxicity of carbon nanomaterials: single-wall nanotube, Multi-Wall Nanotube, and Fullerene, Environ. Sci. Technol. 39 (2005) 1378-1383.

[33] S. Bekou, D. Mattia, Wetting of nanotubes, Curr. Opin. Colloid Interface Sci. 16 (2011) 259-265.

[34] N.B. Mkhondo, T. Magadzu, Effects of different acid-treatment on the nanostructure and performance of carbon nanotubes in electrochemical hydrogen storage, Dig. J. Nanomater. Biostructures 9 (2014) 1331-1338.

[35] K.A. Wepasnick, B.A. Smith, K.E. Schrote, H.K. Wilson, S.R. Diegelmann, D.H Fairbrother, Surface and structural characterization of multi-walled carbon nanotubes following different oxidative treatments, Carbon 49 (2011) 24-36.

[36] S.C. Ramos, G. Vasconcelos, E.F. Antunes, A.O. Lobo, V.J. Trava-Airoldi, EJ Corat Tota re-establishment of superhydrophobicity of vertically-aligned carbon nanotubes by Co2 laser treatment, Surf. Coat. Technol. 204 (2010) 3073-3077.

[37] W. Xia, Y. Wang, R. Bergsträßer, S. Kundu, M. Muhler, Surface characterization of oxygen-functionalized multi-walled carbon nanotubes by high-resolution X-ray photoelectron spectroscopy and temperature-programmed desorption, Appl. Surf. Sci. 254 (2007) 247-250.

[38] A.O. Lobo, M.A.F. Corat, S.C. Ramos, JT. Matsushima, A.E.C. Granato, C. PachecoSoares, E.J. Corat, Fast preparation of hydroxyapatite/superhydrophilic vertically aligned multiwalled carbon nanotube composites for bioactive application, Langmuir 26 (2010) 18308-18314.

[39] A.O. Lobo, M.A.F. Corat, E.F. Antunes, S.C. Ramos, C. Pacheco-Soares, E.J. Corat, Cytocompatibility studies of vertically-aligned multi-walled carbon nanotubes: raw material and functionalized by oxygen plasma, Mater. Sci. Eng. C 32 (2012) 648-652.

[40] I.A.W.B. Siqueira, M.A.F. Corat, B.d.N. Cavalcanti, W.A.R. Neto, A.A. Martin, R.E.S. Bretas, F.R. Marciano, A.O. Lobo, In vitro and in vivo studies of novel poly(D,L-lactic acid), superhydrophilic carbon nanotubes, and nanohydroxyapatite scaffolds for bone regeneration, ACS Appl. Mater. Interfaces 7 (2015) 9385-9398.

[41] L.M. Hollanda, A.O. Lobo, M. Lancellotti, E. Berni, E.J. Corat, H. Zanin, Graphene and carbon nanotube nanocomposite for gene transfection, Mater. Sci. Eng. C 39 (2014) 288-298.

[42] E.F. Antunes, V.G. de Resende, U.A. Mengui, J.B.M. Cunha, E.J. Corat, M. Massi, Analyses of residual iron in carbon nanotubes produced by camphor/ferrocene pyrolysis and purified by high temperature annealing, Appl. Surf. Sci. 257 (2011) 8038-8043.

[43] A.O. Lobo, H. Zanin, I.A.W.B. Siqueira, N.C.S. Leite, F.R. Marciano, E.J. Corat, Effect of ultrasound irradiation on the production of nHAp/MWCNT nanocomposites, Mater. Sci. Eng. C Mater. 33 (2013) 4305-4312.

[44] S.C. Ramos, A.O. Lobo, G. de Vasconcelos, E.F. Antunes, V.J. Trava-Airoldi, E.J. Corat, Influence of polar groups on the wetting properties of vertically aligned multiwalled carbon nanotube surfaces, Theor. Chem. Accounts 130 (2011) 1061-1069.

[45] A.O. Lobo, H. Zanin, I.A.W.B. Siqueira, N.C.S. Leite, F.R. Marciano, E.J Corat, Effect of ultrasound irradiation on the production of nHAp/MWCNT nanocomposites, Mater. Sci. Eng. C 33 (2013) 4305-4312.

[46] A.L. Rosa, G.E. Crippa, P.T. De Oliveira, M. Taba Jr., L.-P. Lefebvre, M.M. Beloti, Human alveolar bone cell proliferation, expression of osteoblastic phenotype, and matrix mineralization on porous titanium produced by powder metallurgy, Clin. Implants Res. 20 (2009) 472-481.

[47] C.A. Gregory, W. Grady Gunn, A. Peister, D.J. Prockop, An Alizarin red-based assay of mineralization by adherent cells in culture: comparison with cetylpyridinium chloride extraction, Anal. Biochem. 329 (2004) 77-84.

[48] P. Zhao, W. Liu, Q. Wu, J. Ren, Preparation, mechanical, and thermal properties of biodegradable polyesters/poly(lactic acid) blends, J. Nanomater. 2010 (2010) 8.

[49] Y.-X. Weng, Y.-J. Jin, Q.-Y. Meng, L. Wang, M. Zhang, Y.-Z. Wang, Biodegradation behavior of poly(butylene adipate-co-terephthalate) (PBAT), poly(lactic acid) (PLA), and their blend under soil conditions, Polym. Test. 32 (2013) 918-926.

[50] H. Fong, I. Chun, D.H. Reneker, Beaded nanofibers formed during electrospinning, Polymer 40 (1999) 4585-4592.

[51] X.-M. Li, D. Reinhoudt, M. Crego-Calama, What do we need for a superhydrophobic surface? A review on the recent progress in the preparation of superhydrophobic surfaces, Chem. Soc. Rev. 36 (2007) 1350-1368.

[52] K. Acatay, E. Simsek, C. Ow-Yang, Y.Z. Menceloglu, Tunable, superhydrophobically stable polymeric surfaces by electrospinning, Angew. Chem. Int. Ed. 43 (2004) 5210-5213.

[53] F. Chivrac, Z. Kadlecová, E. Pollet, L. Avérous, Aromatic copolyester-based nanobiocomposites: elaboration, structural characterization and properties, J. Polym. Environ. 14 (2006) 393-401.

[54] A. Baji, Y.-W. Mai, M. Abtahi, S.-C. Wong, Y. Liu, Q. Li, Microstructure development in electrospun carbon nanotube reinforced polyvinylidene fluoride fibers and its influence on tensile strength and dielectric permittivity, Compos. Sci. Technol. 88 (2013) $1-8$.

[55] C.D. Hoemann, H. El-Gabalawy, M.D. McKee, In vitro osteogenesis assays: influence of the primary cell source on alkaline phosphatase activity and mineralization, Pathol. Biol. 57 (2009) 318-323.

[56] U. Meyer, A. Büchter, H.P. Wiesmann, U. Joos, D.B. Jones, Basic reactions of osteoblasts on structured material surfaces, Eur. Cells Mater. 9 (2005) 39-49.

[57] M. Matsuoka, T. Akasaka, Y. Totsuka, F. Watari, Strong adhesion of Saos-2 cells to multi-walled carbon nanotubes, Mater. Sci. Eng. B 173 (2010) 182-186. 